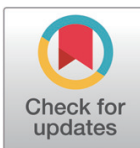

${ }^{*}$ Corresponding author Seung Hwan Lee

Department of Animal Science and Biotechnology, Chungnam National University, Daejeon 34134, Korea. Tel: +82-42-821-5772

E-mail: slee46@cnu.ac.kr

Yang-Mo Koo

Korea Animal Improvement Association, Seoul 06668, Korea.

Tel: +82-2-588-9301

E-mail: greatman009@gmail.com

Copyright (c) 2021 Korean Society of Animal Sciences and Technology. This is an Open Access article distributed under the terms of the Creative Commons Attribution Non-Commercial License (http:// creativecommons.org/licenses/by$\mathrm{nc} / 4.0 /$ ) which permits unrestricted non-commercial use, distribution, and reproduction in any medium, provided the original work is properly cited.

ORCID

Jeongwoen Shin

https://orcid.org/0000-0001-7131-4080

Dongwon Seo

https://orcid.org/0000-0003-0548-7068

Dong Jae Lee

https://orcid.org/0000-0002-8140-014X

SooHyun Lee

https://orcid.org/0000-0001-5257-2068

Cedric Gondro

https://orcid.org/0000-0003-0666-656X

Seung Hwan Lee

https://orcid.org/0000-0003-1508-4887

Yang-Mo Koo

https://orcid.org/0000-0001-7223-1586

\section{Withdrawal: Update physical genomic information for commercial bovine SNP chip based on recent reference genome sequences (ARS-UCD1.2)}

\author{
Jeongwoen Shin ${ }^{1}$, Dongwon Seo ${ }^{1}$, Dong Jae Lee ${ }^{1}$, SooHyun Lee ${ }^{2}$, \\ Cedric Gondro ${ }^{3}$, Seung Hwan Lee ${ }^{1 *}$ and Yang-Mo Koo ${ }^{4 *}$ \\ ${ }^{1}$ Department of Animal Science and Biotechnology, Chungnam National University, Daejeon 34134, Korea \\ ${ }^{2}$ Animal Genetics \& Breeding Division, National Institute of Animal Science, Cheonan 31000, Korea \\ ${ }^{3}$ Department of Animal Science, Michigan State University, East Lansing, MI 48824, USA. \\ ${ }^{4}$ Korea Animal Improvement Association, Seoul 06668, Korea
}

\section{WITHDRAWAL}

After the initial acceptance of the manuscript titled 'Update physical genomic information for commercial bovine SNP chip based on recent reference genome sequences (ARS-UCD1.2)' to Journal of Animal Science and Technology (JAST) on March 23rd, 2021, the article readers stated some concerns regarding the mapping accuracy of illumine SNP chip to recent reference genome (ARS-UCD1.2). Therefore, after consultation with the editorial board members, JAST has decided to withdraw the manuscript due to the significant concerns relating to the claims. 